IZA DP No. 6312

Random or Referral Hiring:

When Social Connections Matter

Catia Nicodemo

Rosella Nicolini

January 2012 


\title{
Random or Referral Hiring: When Social Connections Matter
}

\author{
Catia Nicodemo \\ Universitat Autònoma de Barcelona \\ and IZA \\ Rosella Nicolini \\ Universitat Autònoma de Barcelona
}

Discussion Paper No. 6312
January 2012

IZA
P.O. Box 7240
53072 Bonn
Germany

Phone: +49-228-3894-0

Fax: +49-228-3894-180

E-mail: iza@iza.org

\begin{abstract}
Any opinions expressed here are those of the author(s) and not those of IZA. Research published in this series may include views on policy, but the institute itself takes no institutional policy positions.

The Institute for the Study of Labor (IZA) in Bonn is a local and virtual international research center and a place of communication between science, politics and business. IZA is an independent nonprofit organization supported by Deutsche Post Foundation. The center is associated with the University of Bonn and offers a stimulating research environment through its international network, workshops and conferences, data service, project support, research visits and doctoral program. IZA engages in (i) original and internationally competitive research in all fields of labor economics, (ii) development of policy concepts, and (iii) dissemination of research results and concepts to the interested public.
\end{abstract}

IZA Discussion Papers often represent preliminary work and are circulated to encourage discussion. Citation of such a paper should account for its provisional character. A revised version may be available directly from the author. 


\section{ABSTRACT}

\section{Random or Referral Hiring: When Social Connections Matter}

This study investigates the existence of hiring criteria associated with the degree of social connections between skill and low-skill workers. We provide evidence about to what extent managers rely on their social connections in recruiting low-skill workers rather than on random matching. As one unique feature we follow an approach for a posted wage setting that reflects the main features of the Spanish labor market. By working with sub-samples of high and low-skill workers we are able to assess that the recruitment of low-skill immigrants quite often follows a referral strategy and we identify interesting irregularities across the ethnic groups. As a common feature, referral hiring is usually influences by the ethnicity of the manager and the relative proportion of immigrants within the firm. Under these perspectives, our study outlines new insights to evaluate the future perspectives of the Spanish labor market.

JEL Classification: J15, J21, J24, J61, J71

Keywords: ethnicity, hiring strategies, social networks

Corresponding author:

Catia Nicodemo

Deptartment of Applied Economics

Universitat Autónoma de Barcelona

Edifici B-Campus UAB

08193 Bellaterra (Barcelona)

Spain

E-mail: catia.nicodemo@uab.cat

\footnotetext{
* We are very grateful to A. Bisin, K.Tomas, C. Giulietti, I. García Pérez, K. Lang and G. Topa for their insightful suggestions. We thank the participants to the AIEL Conference (2010), SAE (2011) and 8th IZA Annual Migration Meeting (Washington) and seminar at University of Balearic Islands for useful comments. This research was performed when C. Nicodemo was visiting Department of Economics at New York University and R. Nicolini was at Department of Economics at Boston University. We acknowledge the two departments for their hospitality. All errors are our own responsibility. Financial support from the Fundación Ramón Areces (Ayuda Investigación 2010) is gratefully acknowledged.
} 


\section{Introduction}

Economic efficiency usually requires the labor market to identify the best match for firms and workers, but this is not always possible when firms and workers cannot freely observe all the relevant aspects of the potential candidates. One could easily think of the hiring process as a simple random process based on the selection of applicants once a vacancy is posted. However, the selection process is not so neutral. It may be that the applicants for a vacancy are not a simple random sample of job seekers; rather they can also be a sample of candidates that have learnt about the job's availability via informal market channels. In the same way, the selection of the candidates can be led by a manager on the basis of additional personal information with the purpose of achieving the highest benefits from the hiring process. This is a typical occurrence that arises quite often in the job market, in particular in Spain. According to the most recent statistics from Eurostat (2011), the percentage of Spanish people searching for a job by asking relatives and friends is around $86 \%$ (see Figure 1). The different hiring procedures generate interesting effects on the labor market outcomes and they are well discussed in the literature. In a survey on a sample of European countries, Bonoli and Hinrichs (2010) identify that unsolicited applications and recommendations from already employed workers are considered a positive signal during the selection process of low-skill workers. Oyer (2011) recalls that Montgomery (1991) established that firms can mitigate asymmetric information prob- lems by accessing workers' social networks when making hiring decisions. A few country-studies support this evidence. Analyzing Swedish data, Åslund et alli. (2009) assess that immigrant managers are more likely to hire low-skill immigrants (with respect to native managers) in a sample of Swedish firms, even if the group of immigrants is underrepresented in managerial positions. The same also occurs in other countries such as Germany (as discussed by Dustman et al., 2010) or Canada (Goel and Lang, 2009). In particular, it appears that even similar establishments in the same localities differ in their recruitment decisions depending on the origin of the manager (and this happens both in the public or private sector). This effect is widely discussed in the contribution by Giuliano et al. (2008). Referring to a sample of retail shops in the US, and looking at their labor force composition jointly with the turnover rate of the shop managers, they found that nonblack managers (when in charge of the recruiting process of the shop) hire more white 
employees than black managers do. They also find that the high density of an ethnic group (such as Hispanic) produces a secondary important effect: Hispanic managers hire more Hispanics and fewer whites than a white manager would do. ${ }^{1}$ In the light of the previous results, Spain is an interesting case study for testing the importance of the referral hiring practice when different ethnic groups of workers coexist. Due to the huge flow of immigration that Spain has had in the last ten years the labor market composition has experienced important changes. ${ }^{2}$

The economic impact of immigrants in a host labor market is usually a controversial issue. The principal debate develops around two positions. On the one hand, according to Borjas (2003), the US experience allows the assessment that there is a clear substitution (competition) effect between natives and immigrants. Entrepreneurs perceive immigrants as more flexible and less costly than natives for job positions, and therefore they usually prefer the former to the latter to fill the positions. On the other hand, Peri and Sparber (2009) assess that US census data demonstrate that immigrants specialize in occupations that are intensive in manual skills while natives do specialize in communication-language tasks. Their argument arises from a simple transformation of a basic trade-specialization model whose principal results are the complementarity between these two categories of workers. Nevertheless, in our opinion, the assessment of the type of recruiting strategies adopted at firm level also helps to complete the understanding of the position of immigrants versus natives. If we believed that the substitution effect between natives and immigrants and referral hiring was the most common practice, native or immigrants managers would guarantee a sort of labor segregation status for low-skill qualification. Recent studies document the large effect of ethnic segregation across workplaces in the US or Germany for example (see Hellerstein and Neumark, 2008 or Dustmann et al., 2009). Of course, the degree of segregation of immigrants could be smoothed by two factors: the scarcity of natives applying for such positions (namely, low-skill positions) or the progressive replacement of immigrants to natives in the managerial positions that would bring with them their social connections. In the case of Spain, to our knowledge, there is little literature about the most common hiring practices and the importance of social connections

\footnotetext{
${ }^{1} \mathrm{~A}$ similar result (even if for a narrower ethnic setting) has been found in Carrington and Troske (1998). In the US market, they found that black employers are more likely to hire black workers when the size of the ethnic group allows them to perform this discrimination choice.

${ }^{2}$ According to INE statistics released in 2010.
} 
underpinning the recruiting strategies. The main reason is the lack of reliable data. However, in 2005, the Spanish Social Security office released part of its records, which allowed contributions in this field to flourish. This study contributes to the current discussion on the hiring strategies in two ways. First, we aim to provide a theoretical framework for understanding which factors endorse the adoption of a referral strategy. One unique aspect of this contribution is the definition of a theoretical setting fitting the strong rigid features of the Spanish labor markets, which is different from those of other studies performed up to now (for instance, Dustmann et al. (2011)). Second, we perform an econometric analysis to identify the existence and importance of ethnic-social connections at the heart of the referral process. We select the information at individual level included in the Spanish Social Security records (MCVL) for the period 2000 to 2008.

Our results emphasize the evidence that social connections matter only for the ethnic groups whose size is quite large and social ties are strong. In this respect, referral hiring may be considered a practical way to overcome the limitations of an imperfect labor market subject to important rigidities. The interesting features are that the canonical referral hiring (as defined in our empirical exercise) does not identify the recruitment practice for low-skill workers. For the EU15 candidates ${ }^{3}$ the random hiring channel prevails. A few reasons can be put forward. On the one hand, weak social ties often characterize this group (because of cultural and linguistic differences among its members). This effect may smooth the strength of the referral practice. On the other hand, it is also likely that the EU15 immigrants assimilate more with natives than with the other immigrant ethnicities and, then, the referral hiring channel cannot be the preferential recruiting option. Nevertheless, the wide adoption of the referral practice as a substitute to the competitive market device might yield ethnic discrimination effects in the labor market composition that could encompass limitations in true accessibility to open vacancies. The remaining is organized as follows. Section 2 develops a theoretical framework we will refer to in our empirical analysis. Section 3 describes the Spanish labor market and the data used in our analysis. Section 4 presents the econometric results. Finally, Section 5 concludes.

\footnotetext{
${ }^{3}$ We identify EU15 immigrants as people born in one of the countries that were part of the European Union in 1995.
} 


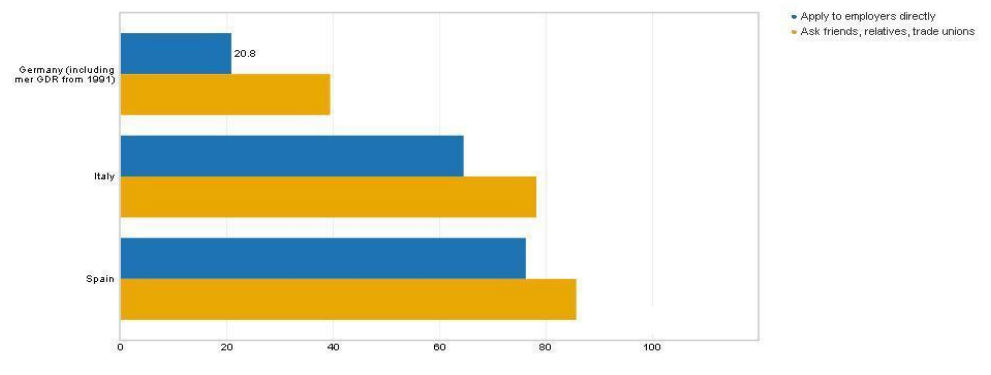

Figure 1: Methods used for seeking works (Source: Eurostat 2011))

\section{The theoretical background}

Our theoretical background inspires by the literature of adverse selection in labor market. We focus on the workers who enter for the first time the job market. It is very important to keep in mind that we are considering a labor market with very rigid institutions. In Spain, almost all contracts are defined after a collective bargaining; then there is small room for productivity to play the discriminatory role as in the pure incentive framework (see appendix A).

The information about wages disclosed by the MCVL reveals that there is not almost variance across workers in the gross wages. In Figures 1-3 we represent the distribution of the wages paid to different group of low skill workers (according to their ethnic group). These data refer to the nominal wages in 2008 as in the records of the Social Security for three of the most representative sectors of activity: industry, construction and hotel. As a consequence of the lack of variance entails that the level wages is not informative enough about the true productivity of workers.

In our setting, any vacancy is the result of a maximization process at firm level; each new vacancy will bring positive or null profits to the corresponding firm. At the moment of organizing a recruitment process for a low-skill vacancy, a manager faces two options. The first is advertising the vacancy. Once the applications have been reviewed, the manager ranks the candidates according to pre- established firmlevel selection criteria and fills the vacancy with the best available candidate. ${ }^{4}$ The latter relies on the existence of the social network of a manager (as already studied

\footnotetext{
${ }^{4}$ This option is particularly time and cost demanding. As discussed by Pellizari (2010), firms usually prefer to adopt this practice when recruiting for high productivity positions.
} 


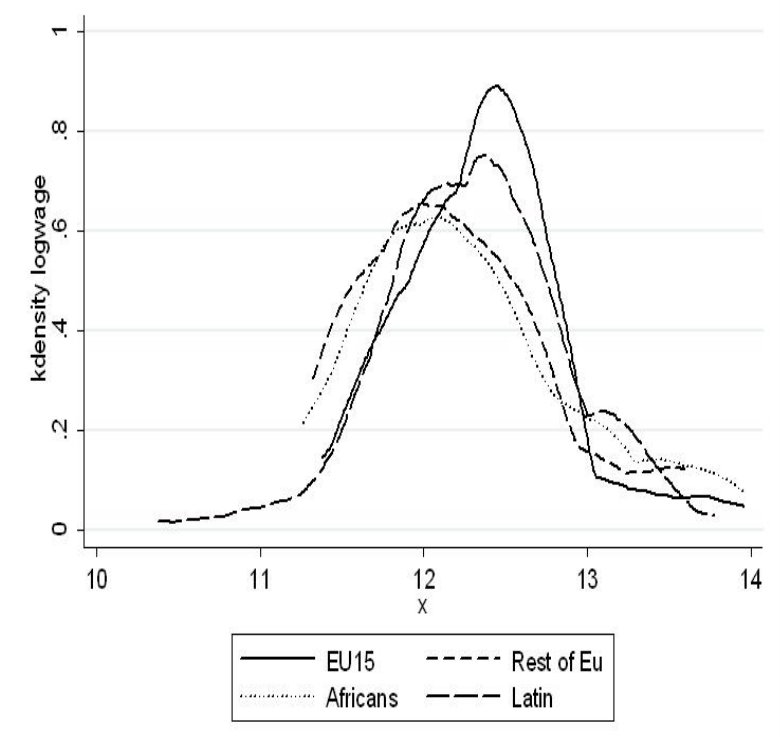

Figure 2: Distribution of nominal wages for full time low skill employees in industry sector in 2008, (Source MCVL)

by Dustmann et al. (2011), Pellizari (2010) or Patel and Vella (2007)). Here, as a social network we consider the group of people irrespective of their ethnicity and qualification having a social tie (or connection) with the manager. In this case, the manager spreads information about the vacancy through her social connections; her contacts may keep the information to themselves or spread it by word-of-mouth to their own (social) connections. In this case the manager hires on the basis of the first-come-first-served candidate.

We label the first option as a random channel recruitment, while the second one is described as referral. Our strategy is to formalize each of the two selection options and, finally, compare their outcomes in order to fix the conditions that make one statistically dominant over the other. We limit the number of potential strategies by assuming that a worker can apply for just one low-skill vacancy in one firm. The wage is set unilaterally by the employer before the worker and the employer meet. A firm usually sets a wage that just fits with a low-skill occupation (preventing skill workers from applying) and the worker accepts it if it is larger than her reservation wage. Our initial hypothesis considers the presence of a large and fixed number of identical firms that offer vacancies (at the rate of one vacancy per firm). Henceforth, we introduce a general selection criteria. 


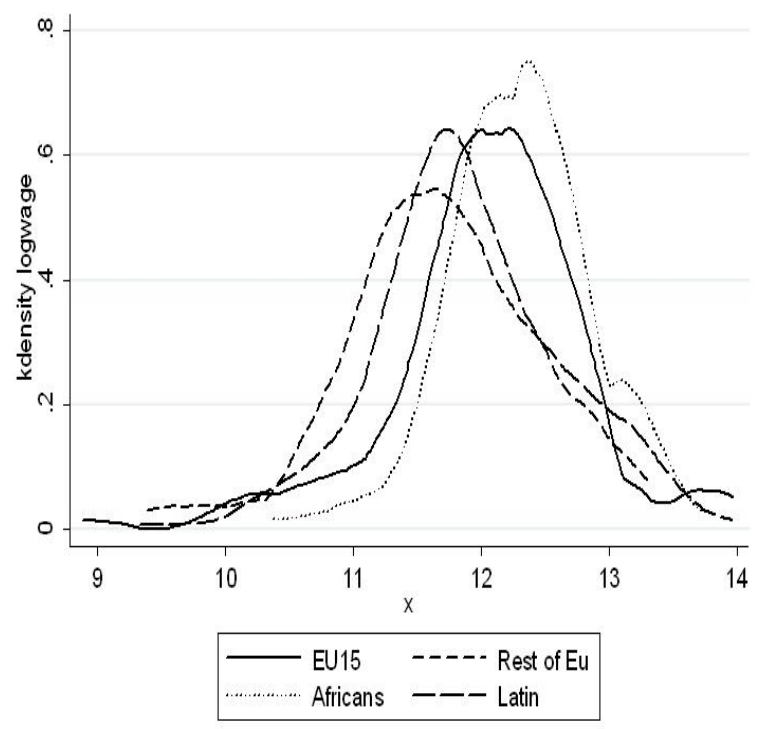

Figure 3: Distribution of nominal wages for full time low skill employees in construction sector in 2008, (Source MCVL)

We split the job candidates into two groups: the compatriots of the manager $\left(z_{L}\right)$ and the rest of candidates $\left(y_{L}\right)$. We define as a compatriot any worker whose nationality coincides with that of the manager that is running the recruiting process. 5

The total number of compatriots and the rest of the workers are Poisson-distributed with (large) mean $Z_{L}$ and $Y_{L}$ for the compatriots and the others respectively.

First, we concentrate on the situation in which the manager hires a low-skill employee through a random recruiting process. In the spirit of Lang et al. (2005, 2010) and Lang and Manove (2003), we begin by assuming that workers and firms meet randomly. When offering a vacancy, the firm posts a wage that is the national wage issued by the national bargaining process and we assume that the firms will make positive or null profits (but not negative profits) when hiring someone for that position. Let us focus on the case where a manager posts a low-type job for a wage $w(>0) .{ }^{6}$ We

\footnotetext{
${ }^{5}$ In this respect, this framework is as general as possible. In the empirical part we will proceed to adapt this concept to the data at hand by referring to the nationality of the manager. In our sample, we will find either native or immigrant managers. In this sense, we will be able to clearly identify in the group of low-skill workers the sample of natives and that of four major groups of immigrants.

${ }^{6} \mathrm{We}$ assume that the level of wages is as low as possible to prevent skill workers from applying for this position. In the canonical wage-posted models, the optimality condition guarantees that the salary corresponds to the expected wage.
} 


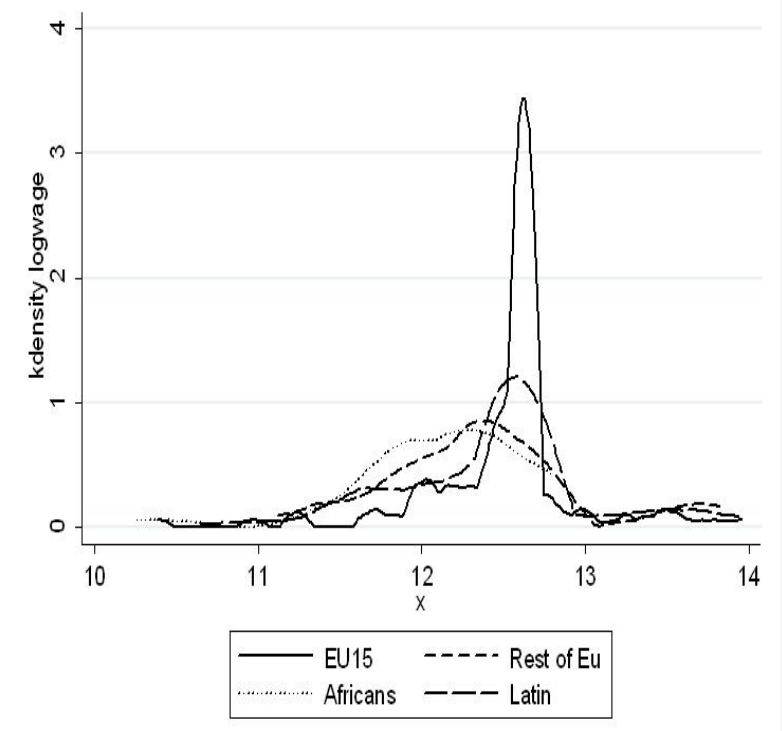

Figure 4: Distribution of nominal wages for full time low skill employees in tourist sector in 2008, (Source MCVL)

assume that the manager is not totally indifferent to the members of the two groups for productivity reasons: it may be that cultural or language differences between the manager and the low-skill workers reduce the performances of these last ones. Managers care about firms' profits and they will select those they consider the most productive workers. We postulate that low-skill compatriots are expected to be more productive than the other candidates (as occurs for natives in Amudeno-Dorantes and de la Rica, 2011). Of course, as soon as these differences shrink the two groups may be virtually identical in productivity. Because of these initial discrepancies in productivity, a manager would prefer to hire a compatriot (if available) rather than another one for an identical fixed wage.

We define the expected number of compatriots applying for a low-skill job as

$$
z_{L}=p(w) Z_{L}
$$

and that of the others is

$$
y_{L}=p(w) Y_{L}
$$

Then, the probability of hiring a compatriot or another candidate would be respec- 
tively: ${ }^{7}$

$$
P_{Z}(\text { random })=\frac{1-e^{-z_{L}}}{z_{L}} ; P_{Y}(\text { random })=e^{-z_{L}} \frac{1-e^{-y_{L}}}{y_{L}}
$$

Another candidate would be hired just in case a compatriot does not apply for an open vacancy, because of the ex-ante ranked preferences of a manager. Instead, if the recruiting process is run by a manager through the referral pro- cess, we need to define the type of social connections composing the manager's social network.

We model the referral hiring possibility by adapting the framework presented by Casella and Hanaki (2008). When a manager decides to run a hiring process through referrals personal connections are very important. More information about the productivity of a worker as well as other selecting features (otherwise not signalled information) are available. In our particular case, we associate the referral dimension (and hence the size of the social connections of a manager) with a measure of cultural or ethnic similarity (Giuliano et al., 2008). The rationale is straightforward: it is more likely to get in touch or to share social connections with persons belonging to the same ethnic group (see Borjas (1992, 1995) and Bandiera (2009)). Let us assume that the size of the group of low-qualified workers is $\mathrm{N}$ and it is composed by compatriots and others. In order to be consistent with the previous notation $N=z_{L}+y_{L}$. We define as $\frac{\alpha}{N}($ with $\alpha$ in $(0,1))$ the probability that a low-skill compatriot has a connection with the manager. In the same manner $\frac{(1-\alpha)}{N}$ is the probability that other low-skill workers have a connection with the same manager. In the spirit of Montgomery (1991), $\alpha$ is the parameter which labels the "in-breeding bias". 8 If $\alpha>\frac{1}{2}$, this means that the manger is more likely to be connected with a compatriot than with another potential candidate.

For a quite large population (i.e. for large $N$ ), the number of ties connecting the managers with low skill natives and immigrants is described by a Poisson distribution. As in Casella and Hanaki (2008), when considering a manager with several connections to each group of low-skill workers, the probability $\widehat{p_{Z}}$ that a compatriot low-skill worker connected with the manager receives an offer (when the managers decides to recruit through a referral process) is:

\footnotetext{
${ }^{7}$ Once more, we are assuming that each worker applies for a job if her expected wage corresponds to the posted one in her category.

${ }^{8}$ Another related literature considers the economic implications of different networks structure and different paths of transmission of information. Calvo-Armengol and Jackson (2004) is an example.
} 


$$
\widehat{p_{Z}}=1-e^{-1}
$$

As an interesting result, the probability $\widehat{p_{Z}}$ is totally independent of the composition of the pool of social connections (driven by the size of the parameter $\alpha$ ). It just relies on the features of the Poisson distribution. This result yields the probability $\left(\widehat{p_{Y}}\right)$ that another low-skill worker receives an offer under the previous conditions is identical to $\widehat{p_{Z}}$.

However, connection matters. Therefore, on both manager and employee sides, the probability that a manager working through a referral process will hire a compatriot low-skill worker (conditional on having at least one connection) is $\alpha$ (and similarly $(1-\alpha)$ for the others). As proved in Casella and Hanaki (2008), at the equilibrium, the firm profit maximization problem means the expected profits from referral hiring must coincide with the probability of hiring a worker whose value (a combination of his productivity and future referrals) should be at least identical to the posted wage. 9 Under this condition the probability of hiring a low-skill compatriot through referral - $P_{Z}($ referral $)$ - turns out to be:

$$
P_{Z}(\text { referral })=\alpha\left(1-e^{-1}\right)
$$

and, similarly, for the other low-skill workers the probability is:

$$
P_{Y}(\text { referral })=(1-\alpha)\left(1-e^{-1}\right)
$$

Once establishing the hiring probabilities through referrals, the next step is to consider which conditions determine that the probability of being recruited through referrals is higher than the random one (namely, without any connection between the manager and the low-skill worker). In order to address this issue, we split the treatment of the problem into two parts: the former considering the case of the recruiting process for compatriots and the latter for the others. First, we need to identify the point at which the two probabilities (random and referral) are the same. To this end we have to compare the two probabilities:

\footnotetext{
${ }^{9}$ The original contribution by Casella and Hamaki (2008) considers the referral wage (as reserve wage identical for natives and immigrants). The wage structure is such that the expected value of the referral is slightly larger than the proposed wage. In our case, the referral wage has to be identical to the posted wage, because no (official) labor market exists outside of this equilibrium. As for our framework, we are assuming that when a firm opens a vacancy, this choice is profit maximizing.
} 


$$
P_{Z}(\text { referral })=\alpha\left(1-e^{-1}\right), P_{Z}(\text { random })=\frac{1-e^{-z_{L}}}{z_{L}} .
$$

On the one hand, the referral probability is basically a constant and the value is increasing with the size of connections among compatriots. On the other hand, the random probability is always decreasing in the total size of the compatriot-low-skill population, since:

$$
\begin{aligned}
& \frac{d P_{Z}(\text { random })}{d z_{L}}=\frac{e^{-z_{L}}\left(1-z_{L}\right)-1}{\left(z_{L}\right)^{2}}<0, \\
& \text { for } e^{-z_{L}}\left(1-z_{L}\right)-1<0 ; \frac{1-z_{L}}{e^{z_{L}}}<1 .
\end{aligned}
$$

By the monotonicity of the random probability, it is necessary that there is a minimum number of low-skill compatriots in order to make the referral probability higher than the random one. This implies that there is a need to have a minimum size of the network to make the referral structure effective. However, the minimum size of this group decreases with respect to the increase of the proportion of this group in the total population of low-skill workers. For any given degree of $\alpha$ the referral probability is increasingly dominant over the random one. As second step, we focus on the comparison between the random and referral probabilities when a manager hires another low-skill candidate that is not a compatriot. In this case we have to compare the following two probabilities:

$$
P_{Y}(\text { referral })=(1-\alpha)\left(1-e^{-1}\right) ; P_{Y}(\text { random })=e^{-z_{L}} \frac{1-e^{-y_{L}}}{y_{L}} .
$$

As one could expect, the probability of hiring another skill candidate through referral increases with respect to the size of those workers in the low skill population (namely, decreasing in the share of the low-skill compatriots). The same happens for the random probability, as one easily can check:

$$
\frac{d P_{Y}(\text { random })}{d z_{L}}=-e^{-z_{L}} \frac{1-e^{-y_{L}}}{y_{L}}<0 .
$$

Instead, in the case of the random probability, the effect of changes in the size of their group in the low-skill population is not so clear. Formally, 


$$
\frac{d P_{Y}(\text { random })}{d y_{L}}=\frac{e^{-z_{L}}}{y_{L}}\left[-\frac{1-e^{-y_{L}}}{y_{L}}+e^{-y_{L}}\right]<0 .
$$

As before, the sign of the previous expression is always negative (that implies that the random probability to hire another low-skill candidate is decreasing with respect to the number of the low-skill compatriots). However, in this case, the central issue is that the comparison of the two probabilities (i.e. random and referral) relies both on the size of the two groups. For the low level of $\alpha$ (i.e low probability of social connections with compatriots) the referral probability (for the members of the other group) is always higher than the random one. Instead, for high values of $\alpha$ (i.e. high probability of social connections with compatriots) the referral probability is higher than the random probability when the number of compatriots is less than that of the others, and this happens if the other group achieves a minimum size threshold.

We may sum up the previous results and formulate some testable predictions:

- Hiring through referrals is effective if and only if the connections involve a minimum number of individuals and the "in-breeding" parameter $\alpha$ is relatively large. 10

- The probability to select a candidate belonging to one of the two groups is proportional to the relative size of this group in the total population.

- Random hiring is effective when the size of both the groups is small.

Keeping in mind these theoretical predictions, in Section 4 we proceed to perform some econometric estimation for measuring the importance of the network effects for the hiring policies of the immigrants in Spain.

\section{Spanish labor market and our sample data}

In the last decade, Spain hosted a progressively increasing number of immigrants from different origins. As well described by Amudeno-Dorantes and de la Rica (2011) the entrance of immigrants in Spain has been impressive. At the end of 2008 immigrants

\footnotetext{
${ }^{10}$ In this respect $\alpha$ maybe a measure of the ethnic segregation within the member of the group (see Nicodemo 2009).
} 
represented $10 \%$ of the population: a unique record. A few studies (AmudendoDorantes and de la Rica, 2011 or Farré et alli, 2011) find evidence that immigrants are not perfect substitutes for natives, in the national labor market. This huge immigrant wave shifted the (most skill) natives towards non-manual skill positions, leaving the most manual tasks to immigrants. In particular, the entrance of more manual skill immigrants allowed native-women to search for jobs according to their educational degrees and outsource conventional home-tasks (Farré et alli, 2011).

IIn the light of these results, one would expect a massive shift of natives versus high- skill positions and a strong enrolment of native-young cohorts in education degree to reinforce these complementary patterns. Instead, data at hand show a different pattern: the educational performance of Spanish citizens in the 2000s (as in López-Mayan, 2010, for instance) is puzzling and the proportion of young people that complete graduate studies (i.e. at university level) drop impressively from 2005 to 2009. This evolution may be due to two joint effects. On the one hand there could be the entrance of educated women into the job market that directly shifts down the potential demand for young educated employees. On the other hand we may also be experiencing a conjunctural effect. The position of the business cycle leads to less interest (in terms of opportunity costs) investing in education and the Spanish wage structure in 2006 discourages post-compulsory attendance (López-Mayan, 2010).

This second effect will yield a shortage of qualified skill workers in the near future. By linking the shortage effect of skill natives with the sustained opening of vacancies (due to the economic expansion cycle), there is room for immigrants to access qualified positions and, then, through a network effect, push the hiring of immigrants for low-skill positions. In this perspective, the identification of potential hiring strategies based on social connections in the current Spanish market would suggest some insights about its evolution in the near future. The existence of strong influential social-ethnic connections concerning hiring tendencies inside each group (natives or immigrants, respectively) and a progressive replacement of natives in managerial positions by immigrants would eventually drive out natives from the low-skill positions. Given the relative abundance of low-skill natives in the workforce composition, this movement could yield either a massive re-qualification effort (among natives) to be able to access high-skill positions or the consolidation of a high unemployment rate among the native group. In addition, if this recruiting pattern is reinforced in time, there could 
be also secondary effects against a truly assimilation of immigrants in the host labor market and, therefore, perhaps allowing some segregation problems to consolidate. The data used for this study are from the register of Social Security system for active people in the labor market. This database provides information about all the historical relationships of any individual within the Social Security System (in terms of work and unemployment benefits). We dispose data about the type of contract (part-time or full time), the sector of activity, professional category and the monthly earnings paid to the Social Security System, as well as the time at which an individual entered and/or left the job market. In addition, the MCVL gives details about the establishment (location, number of workers, industry and sector) in which a worker is hired. This second group of data makes it possible to track the professional career of any employee over time. By arranging the available items we may easily detect the labor force composition of our sample of firms and, in particular, we may extract information about the qualified and no-qualified employees. We adopt a definition of "qualified" employee for any employee who has an academic degree and is hired at the highest professional categories.

non-qualified or low-skill workers. The temporal dimension of the MCVL panel allows us to track the entry of a manager in a firm and the subsequent organization of recruitment for low- skill employers. In order to be able to select the sample of firms in which the manager is really the principal authority in the management of human resources, we restrict our analysis to a significative sample of active firms (in 2008) with fewer than 100 employees and with at least 4 workers. Then, we operate a selection of new employees for the each establishment from 2000 to 2008 using the wave of 2008 of MCVL, given that the big immigration flows started from 2000 onward. Matching workers and establishments is difficult because the MCVL database has been created to control just for employees, but the ID firm number is a special string code that makes it possible to retrieve part of the missing information. Once such a sample has been obtained, we select the number of individuals (legal immigrants) that kept a position in the same Spanish firm for at least one year. In this way, we track the evolution of the recruiting policy adopted by the firm. Henceforth, we define immigrant as an individual born in a foreign country, while a native is a worker born in Spain. ${ }^{11}$

\footnotetext{
${ }^{11}$ Although the immigration in Spain is quite heterogeneous, we can cluster all the major nationalities into four big groups: Latin, Eu15, Rest of EU and Africans.
} 

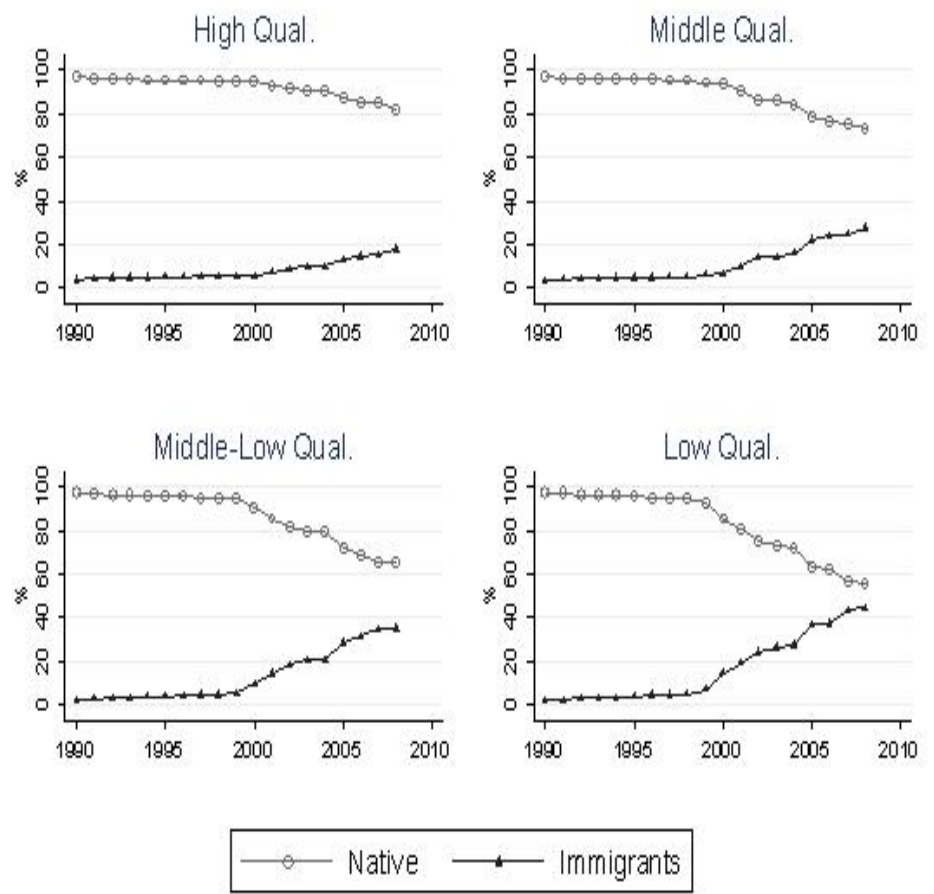

Figure 5: Hiring of natives and immigrants by qualification (Source: MCVL 2008, Calculus: authors)

In our sample, the group of managers organized recruiting processes for 166,747 individuals (at low qualified positions) in the period 2000-2008. Figure 5 illustrates the hiring process across the years (1990-2010) for high and low-skill immigrants and natives. The hiring of low-skill immigrants increased quite a lot after 2000 and that of natives dropped. In the high-skill sample the recruiting trend is qualitatively identical to the previous one but with a lower magnitude. This evidence has roots in a institutional and conjunctural dimension. In 2006 the Spanish government approved a reform for speeding up the recognition of foreign educational degrees and made foreign citizens more suitable to be hired for positions matching their educational track. The acceleration of this reform was driven by the brisk increase of qualified vacancies. At the same time, the easy job opportunities gave a strong incentive to natives to entering into the labor market rather than achieving a graduate degree. Furthermore, data also provide information about a potential ethnic association between high and low-skill recruitment.

Native managers are more prone to hire native low-skill workers (Table 1), and 
the same occurs for immigrant managers versus immigrant candidates. Therefore, the progressive entrance of low-skill immigrants in the labor market may be due to simple supply effects or it is a consequence of the hiring based on ethnic association. In Table 2 we deliver the descriptive statistics of our sample of observations. The total percentage of high-skill immigrants holding a high education degree (secondary plus graduate) replicates the patterns identified for natives, while most of low-skill workers (immigrants and natives) have primary and secondary education. Concerning the distribution across sectors of activities, there is always a slight dominance of natives in filling up vacancies that require a high education degree while immigrants concentrate on the vacancies at medium education degree. Splitting sectors into the finest level, the presence of low-skill immigrants dominates that of low-skill natives in the sector of construction, hotels and finance. Instead, looking at high-skill positions, immigrants are relatively more concentrated in services (such as retail, hotels, transport, education and health).

In this respect, Figure (6) portraits the propensity for hiring by nationality of managers and low-skill workers. Excluding natives, when a manager has to fill a low-skill position, the first choice is for immigrants from South America. There is a clear link concerning the cultural and language proximity between natives and Latin people for increasing the participation of the last group into the Spanish labor market at the highest degree. It is a reasonable thinking of the kind of expected tasks for persons filling up these positions: managers and other administrators are expected to communicate frequently (daily) with the other workers in the enterprise and language fluidity is strongly recommended. For instance, this could explain the preferences for Latin managers rather than European ones.

In this respect, Figure (6) portraits the propensity for hiring by nationality of managers and low-skill workers. Excluding natives, when a manager has to fill a low-skill position, the first choice is for immigrants from South America.

There is a clear link concerning the cultural and language proximity between natives and Latin people for increasing the participation of the last group into the Spanish labor market at the highest degree. It is a reasonable thinking of the kind of expected tasks for persons filling up these positions: managers and other administrators are expected to communicate frequently (daily) with the other workers in the enterprise and language fluidity is strongly recommended. For instance, this could explain the 
Table 1: Sample description

\begin{tabular}{r|rr}
\hline Middle and Low-skill & \multicolumn{2}{|c}{ Manager } \\
\hline & Natives & Immigrants \\
\hline \multirow{3}{*}{ Natives } & $83.67 \%$ & $3.81 \%$ \\
& 139,509 & 6,353 \\
& & \\
Immigrants & $4.38 \%$ & $8.14 \%$ \\
& 7,305 & 13,580 \\
\hline \hline
\end{tabular}

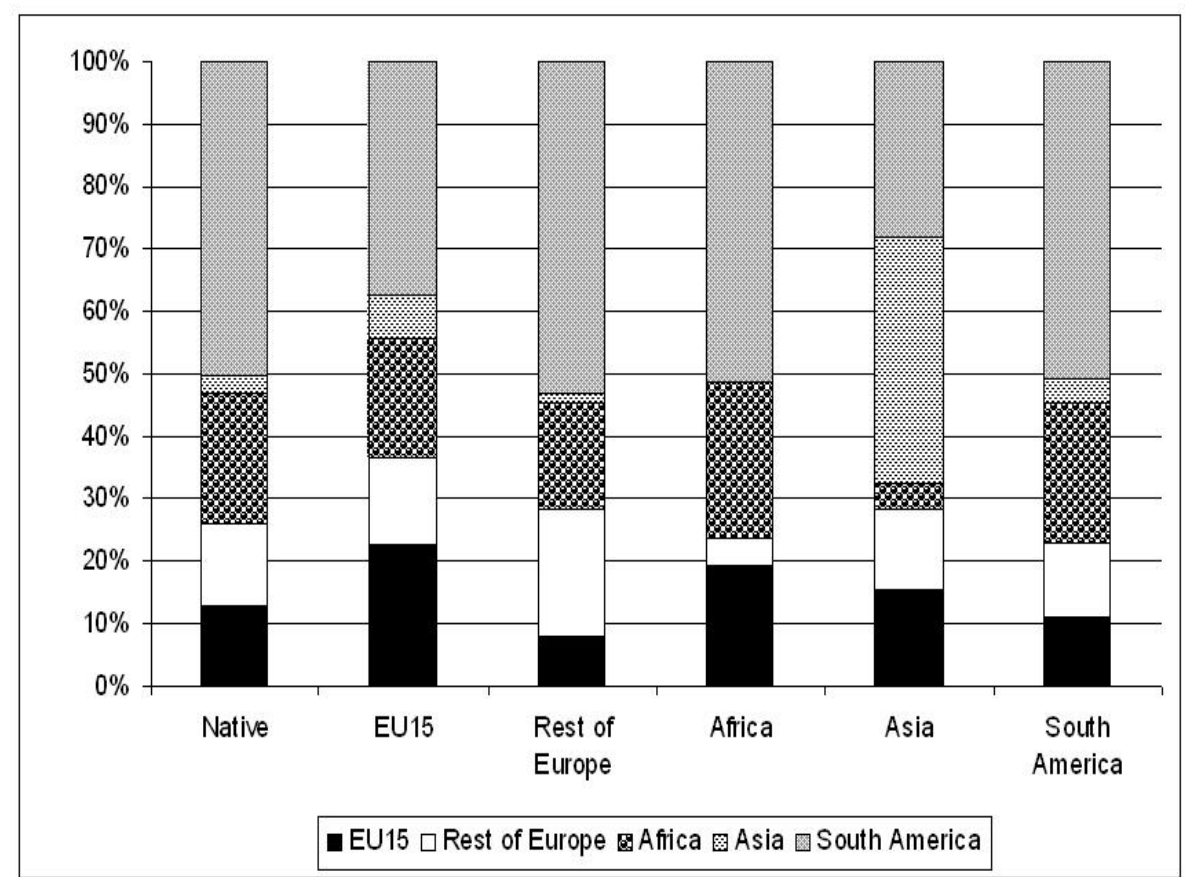

Figure 6: Composition of hiring by country (Source: MCVL 2008, Calculus: authors) 
preferences for Latin managers rather than European ones.

Referring to the other groups, it is worth noticing that in the Asian group the ethnic ties between managers and low-skill workers are incredibly pronounced. Therefore, a general analysis of the empirical evidence clearly emphasizes that there exists a general tendency to favouring cultural and ethnic linkages during the recruiting process in Spanish firms. Then, the purpose of the empirical analysis is to quantify the strength of this effect.

\section{Econometric results}

In the light of the empirical evidence we previously discussed, it seems that ethnic connections (as a proxy of the social networks) matter in recruiting strategies. The same culture, language or relationship make the probability of hiring people with ethnic similarity between managers and workers higher. There are many explanations such as: preference among agents (Becker, 1957), or managers that can evaluate some characteristics better (level of education, experience, etc.) due to sharing them and / or the network across workers. Oyer (2011) stated that Casella and Hanaki (2008) are the seeds of a theory of firm-level hiring strategy, but the empirical literature about firm-level choices in the presence of employees social networks is still in its infancy. In this study we perform a few econometric exercises to target such a scope by working with data at firm level. In this empirical analysis, we principally focus on the group of immigrants in which it is quite easy to track the ethnic feature (still allowing for a certain degree of heterogeneity) and, then, control for the network association. ${ }^{12}$

The aim of this section is twofold. On the basis of our theoretical framework, on the one hand we are aiming to identify the potential dominance of a referral recruitment strategy over the other, and, on the other hand, the features at firm level that potentially may support this dominance. In particular, in our empirical exercise, we are disentangling the different ethnic groups inside the whole sample of immigrants and focusing on the specific features that shape their entry into the Spanish labor market. Our scope is understanding whether the selection of a low-skill immigrant for a vacancy is due to the true preferences for the professional profile of this candidate

\footnotetext{
${ }^{12}$ In this respect, the group of natives is not suitable for the purpose of the section and we do not consider it in our empirical exercise.
} 
(rather than a native, for instance). In addition, we are also interested in disentangling the potential racial preferences that may drive the recruitment of a specific member of an ethic group rather than other candidates. According to the data at hand, we identify four different ethnic groups of candidates that we label as: ${ }^{13}$

- African: all immigrants born in one of the African country,

- Latin: all immigrants born in one of the Latin American country,

- EU15: all immigrants born in one of the 15 countries of the European Union as established by official treaties in 1995 .

- Rest of Europe: all immigrants born in one of the European countries that was not a member of the European Union in 1995.

Our empirical strategy begins with an assessment of the variables influencing the results of the recruitment processes of low-skill workers conditional on a few characteristics of the firms opening vacancies. In particular, we are focusing on the nationality of the manager running the process. The rationale is to stress the potential strength of ethnic affinities between employer and employee at the moment to select a candidate.

In this manner, we are identifying the referral option with the ethnic dimension assuming that immigrants belonging to the same ethnicity, working (or looking for a job) in the same industry, in the same region and at a particular moment in time are likely to be connected by informal contacts. Therefore, they are more suitable to adopt a referral hiring choice, if available. The rationale of this behaviour is quite intuitive: in the absence of effective market selection mechanisms, cultural ties are a sort of alternative device to cope with the hiring risk entailed by asymmetric information. Empirically, we take into account this effect by introducing a measure of the size of an ethnic group by province as a share of the total population. However, there could also exist some cross-cultural connections among individuals that share the same condition (namely immigrants versus natives) in a specific firm that is active in an industry, in a specific place at a given time, independently of their ethnic origin. This may be the case of the group of immigrants inside a firm that may propose suitable candidates to a manager for a vacancy (see Dustmann et al. (2011)). If the manager followed the

\footnotetext{
${ }^{13}$ We excluded Asian immigrants because of scarcity of individual data.
} 
suggestions proposed by this group of workers and hired without going through the official market, the hiring process would take place by means of indirect connections of the manager. Again, the number of direct connections magnifies the proportion of the indirect connections and, therefore, leads to a most likely referral recruiting choice. In our empirical exercise, we identify this last feature (i.e. the potential impact of the indirect connections of a manager) by the share of immigrants already working in a firm.

In the light of the previous assessment, the first step of our analysis is to exactly identify the potential existence of ethnic ties (and therefore, direct connections) encom- passing referral hiring. To this end, we perform a multinomial logit estimation. Wooldridge (2006) assesses that in the multinomial logit models the conditioning variables do not change across alternatives; the covariates are specific to individuals and not to alternatives. Therefore this model can be applied when the characteristics of the alternatives are unimportant or not available. In our case, we want to calculate the probability than an employee $i$ hired in sector $j$ at time $t$ belongs to race group $k$. This can be represented as follows:

$$
\operatorname{Pr}\left(\text { ethnicity }_{i j t=k}\right)=\frac{\exp \left(\text { MangEth }_{j t}^{k} \beta+X_{i t}^{k} \gamma+\alpha_{j}^{k}\right)}{\sum_{b=1}^{k}\left(\exp \left(\text { MangEth }_{j t}^{b} \beta+X_{i t}^{k} \gamma+\alpha_{j}^{b}\right)\right)} .
$$

In running these estimations, we are interested in detecting any potential ethnic connections in hiring strategy as predicted by Montgomery (1991). As a consequence, a somewhat ethnic pattern (embedding the existence of a social network at firm level) appears. One of the novelties of this exercise is aimed at identifying the potential existence of social networks at firm level, however, without having a direct measure (or indicator) of their existence. Results presented in Table 3 emphasize that the ethnic origin of the managers turns out to be important and creates an implicit discriminatory effect. Taking the group of African workers as a baseline, the multinomial logit assesses the potential preference in hiring candidates of other groups with respect to African candidates. The statistical significant associations are quite evident: native managers always prefer to recruit native candidates, and the same association holds for managers whose nationality belongs to one of the EU15 countries. Instead, managers whose ethnicity is that of one of Latin American countries or the Rest of EU countries do not have a clear preference for hiring low-skill workers of their ethnicity, rather than 
African candidates. The size of the share of immigrants already active in the same firm always involves a positive attitude for filling up vacancies with immigrants, but the strength of this preference for each ethnic group is never superior to that for natives. Furthermore, for some groups there is also evidence of some segregation effects. As discussed by Nicodemo (2009), important segregation effects in the labor market are identified within the group of Latin, Africans and East European workers.

Thus, this first exercise highlights important evidence: ethnic association holds for a few groups, but it is not exclusive. The existence of cross-ethnic preferences (Latin versus natives against African, for instance) is evidence that either the recruiting tendencies follow a specific process at firm level and several other effects mask the statistical significance of ethnic preferences or the relative small size of an ethnic group in a place (matching the required qualifications for a vacancy) and yields the hiring of other candidates irrespective of their ethnicity. These two last statements require further investigation. It is important to analyse the possible determinants that shape the recruitment strategy. On the basis of the prediction of our theoretical framework, we run a linear probability model. Finally, we also run some checks for robustness by adding fixed effects at firm and establishment level.

In our case, we calculate the probability that a low-skill employee $i$ which has been recruited in sector $j$ at time $t$ belongs to a specific ethnicity $k$ (namely, Latin, African, etc.).

$$
\operatorname{Pr}\left(H_{i j t k=1}\right)=\phi\left(\text { MangEth } h_{j t} \beta+X_{i t} \gamma+\alpha_{j}\right)
$$

In accordance with the theoretical prediction, first we account for the ethnic characteristics of the manager running the recruitment process and, for the sake of simplicity, we simply distinguish between natives or immigrants. Then, we focus either on the relative size of the ethnic group (with respect to the whole size of the group of the low skill workers) in a province and on relative size of the immigrant group at firm level. The manager variable and the share of hired immigrants at firm level are expected to capture to what extent a firm is prone to hire immigrants. In addition, the presence of the stock of immigrants already active in the firm also capture the potential existence of cross-cultural ties that can push the manager to follow a referral recruiting process for filling up a vacancy. Instead, the relative size of an ethnic group in the active population at very sharp territorial unit (province) allows for capturing 
the relative abundance of immigrants in a specific area as a further device pulling their selection in the recruiting process by a potential ethnic network. When facing a large ethnic group, it could be the case that the hiring of its member is pushed by their connections and information spread easily as word-of-mouth. Finally, in this set of estimations, we control for regional, time and industry dummies as well as a set of their inter- action in order to take into account the possible changes in the local environment, ${ }^{14}$ that could affect the dynamics of the recruitment process.

In the empirical estimations, first we focus on the hiring for low-skill vacancies in the whole group of immigrants, and then we focus on the individual ethnicity. Once again, we point out that all this estimations are run exploiting all information at firm level. In Tables 4-7 we summarize the set of the estimations we performed for the four groups of immigrants. As one may expect, the manager dummy and the share of immigrants at firm level are alternative (statistical) measures for identifying the propensity to hiring immigrants at firm level. In case of an immigrant manager organizing a recruitment process, the relative abundance of all ethnic groups in a place is positive associated with the probability to select an immigrant. Our evidence suggests that there is a clear association between the probability of hiring a low-skill immigrant with the relative size of her ethnic group in her place of residence, except for EU15 low-skill workers. Therefore, for three out of four selection processes the potential ethnic network matters. We identify an interesting selective path: for the case of African, EU15 and the Rest of Europe the presence of immigrants (in the same firm) belonging to other ethnic groups is detrimental for the recruitment of their members. This can hold when thinking of considering low-skill occupations with a high degree of substitutability among candidates. Again, in the case of Latin candidates this competition effect is present just for the African ethnic group but not for the other groups. Latin people may achieve a higher degree of assimilation (for instance, for linguistic or cultural similarities) with the native population that is reflected in a sort of job complementarity with the other two foreign groups (EU15 and the Rest of EU). Furthermore, the Latin and African groups are distinguished by another interesting feature. If for European low-skill employees the stock of immigrants at firm level as well as the type of manager is important for increasing their probability of being

\footnotetext{
${ }^{14}$ This could be the case of particular phases of the business cycles or a specific expansion period of an industry as occurred for the construction sector.
} 
hired, the same does not hold in the case of the other two groups. With regards the probability of hiring a Latin or an African low-skill employee, the immigrant manager may represent an obstacle for their hiring when associated with the size of immigrants already present in the firm. We could think of an implicit upper bound limit (at firm level) for the presence of these two groups of workers that may be potentially explained by their degree of substitutability with respect to the natives. In order to check the robustness of the previous results, we run further linear probit models with fixed effects at firm and establishment level. In the previous discussion, we often claimed that part of the results may be driven by the recruitment criteria established at firm level. ${ }^{15}$ Our idea is to include those effects in order to test the robustness of the statistical determinants yielding the hiring of an immigrant. In the database we built, we are able to identify either the recruitment led by each establishment and by each firm. We run again the previous estimations adding up both type of effects knowing that the former are more stringent than the latter. ${ }^{16}$

Tables 8-11 present the results of this second range of estimations. On the whole, these last estimations confirm the previous results. Thus, by taking into account the specificity of the recruitment process either at firm and establishment level, we are able to replicate the statistical significant hiring factors as in the previous set of estimations. In addition, controlling for recruitment criteria at firm level renders the impact of the stock of immigrant and the manager type in the hiring selection for African and Latin low-skill employee as that for the other ethnic groups. This result confirms our hypothesis that the previous results were associated with some specific conditions at firm level. Instead, the adoption of fixed effects allows the researchers to better qualify the determinants for the hiring of EU15 and Rest of Europe low-skill workers. When accounting for fixed effects, the determinants of recruitment of employees from the Rest of Europe follows the same pattern of Latin or African workers. Instead, we encounter both a reinforced absence of referral effect and a very weak effect of manager type and firm immigrant stock in their hiring for the EU15 workers. There is a clear distinction between the recruitment strategies of low-skill EU15 workers

\footnotetext{
${ }^{15}$ In the theoretical setting we identify this effect with the ranking of preferences established by each manager.

${ }^{16}$ As an establishment we consider a branch of a firm in a specific location. Each branch can share the same recruitment criteria established by the firm it belongs to, but it can also add further condition mostly due to its specific location. Of course, our main assumption is that these general criteria are invariant across time in our sample.
} 
versus the others ethnicities. The EU15 get hired independently of their potential network connections. A few reasons can put forward to better qualify this result. In the light of our theoretical background, we can interpret this result as an outcome of a typical random process where the hiring is mostly driven by the productivity of the workers according to which the manager builds his ranking of preferences. The EU15 immigrants enjoy working conditions similar to those of natives and also their level of education is comparable to that of natives (because of the European free movement settlements). This evidence assimilates more of this group of immigrants to natives than to the others whose professional and education curricula are not always comparable to the natives' ones. In addition, it is also important to consider that the group of EU15 is very heterogeneous. For instance, the members do not speak the same language and this makes the potential cultural and linguistic ties (the basis of our network idea) weaker than those for Latin, for instance. Once more, in absence of this potential effect of the referral condition the hiring of EU15 candidates needs to be based just on their curricula. This last statement endorses one outcome of our theoretical framework: the dominance of the random-style hiring appears when the network connections are particularly weak or the size of the ethnic group is relatively small. And, again, the dominance of the random hiring implies that contracting is mostly based on the productivity-ranking factors.

\section{Conclusions}

This study provides a few insights about the hiring policies at firm level concerning immigrants. In the most recent years, Spain experienced a huge entrance of immigrants and this produced interesting effects on the structure of the local labor market. This analysis delivers some evidence about to what extent the recruit- ing policies adopted for low-skill workers immigrants are impacted by the existence of social connections. Our preliminary estimations assess that the networks effects have a bearing on hiring policy. We identify that the relative size of the groups of immigrants at firm level is a key factor for driving the hiring of other immigrants. However, inside each ethnic group the social ties are not always identical. Our empirical strategy emphasizes that the probability of hiring a low-skill employee is principally driven by the referral strategy in the case of African, Latin and Rest of Europe workers. Instead, contracting EU15 
workers is mostly associated with a random selection that privileges the curricula of the candidates. In terms of efficiency (at firm level) which strategy should be preferred? In a sticky wage system, the challenge of the labor market is to recover the efficiency lost with the dissociation of productivity from wages. In this respect the random practice partially overrides this problem and recruiters hire the best applicant for the vacancy in terms of curricula. However, this system is particularly costly and time consuming. Instead, the referral process is less time consuming but it does not always guarantee the best candidates are appointed. The optimal referral situation would be the case of high densely connected networks that allow managers to get in touch with an extremely large number of applicants (comparable to a random strategy) and, then, choose according to the best qualification. A second line of comments refers more generally to the Spanish market composition and its perspective in the long run. In the light of our results, it is evident that there exists a significant hiring association between immigrant managers and immigrant low-skill employees. The progressive reduction of the stock of qualified native workers (to be hired as skill workers) may also involve a reduction in the probability of hiring low-skill natives, if skill positions are filled up by immigrants. To this extent, this contribution joins the conclusion of other studies (such as Amudeno Dorantes and de la Rica, 2011) on the importance for natives to distinguish themselves from immigrants in their qualifications. In addition to the standard complementarity versus substitution effect that justifies this strategy, there is also the indirect effect previously detected that may drive the low-skill natives out of the market if no (or very few) skill natives occupy managerial positions. As a next step, it could be of interest to investigate the effects encompassed by the wide adoption of the referral hiring on productivity. To the same extent, more detailed data at individual level would also assist in properly identifying the social network composition of each job seeker and, then, allow better shaping of the referral dimension. 


\section{A Appendix: Spanish labor institutions}

The principal features of the labor market in Spain have been recently discussed by O. Fanjul in a document published en 'El País - Negocios" (on January 23th 2011).

We may summarize them in a few points:

1. Contracts issued by a collective barging ("convenios") are true legal agreements between two agents (the employer and the employee). A new firm cannot grant labor conditions to her workers that are different from those established in that agreement of the correspondent sector. For example: in Spain, a new bank cannot decide a different open time and days for its own branches (for instance, on Sunday morning) or salary scheme of its own employees different from those are established in the national agreement of the banking sector.

2. Some major decisions at firm level cannot be taken without the approval of the local administration authorities. Let us consider the following working example. A firm needs to reduce the number of employees because of a bad economic situation. First, this decision needs to be discussed with the local representatives of the labor unions and, then, to get the approval of a local or national administrative authorities.

3. Before planning cuts in the number of employees, it is compulsory that the firm has already had operative losses in the previous years. It cannot make adjustments in advance. 


\section{References}

[1] Amuedo-Dorantes, C., de la Rica, S. (2011): "Complements or Substitutes? Immigrant and Native Task Specialization in Spain", Journal of Labor Economics, vol.18(5), pp. 697-707.

[2] Åslund, O, Hensvik, Nordström Skans, O. (2009): "Seeking similarity: How immigrants and natives manage at the labor market", CReAM Discussion Paper n. $06 / 09$.

[3] Bandiera, O., Barankay, I. and Rasul, I. (2009): "Social Connections and Incentives in the Workplace: Evidence from Personnel Data", Econometrica, 77(4), 1047-1094.

[4] Beker, G. (1957): "The Economics of Discrimination", Chicago University Press.

[5] Bonoli, G. and Hinrichs, K. (2010): "Statistical Discrimination and Employers' Recruitment Practices for Low-Skilled Workers", REC-WP 10/2010.

[6] Borjas, G. J. (1992): "Ethnic Capital and Intergenerational Mobility", Quarterly Journal of Economics, 107(1), 123-150.

[7] Borjas, G. J. (1995): "Ethnicity, Neighborhoods, and Human-Capital Externalities", American Economic Review, 85(3), 365-390

[8] Borjas, G. J. (2003): "The Economics Benefits from Immigration", Journal of Economic Perspecticve, vol. 9(2), pp. 3-22.

[9] Bratsberg, B, Raaum, O (2010): "Immigration and wages. Evidence from Construction", CReAM Discussion paper.

[10] Calvo-Armengol, A., and Jackson, M. (2004): "The Effects of Social Networks on Employment and Inequality", American Economic Review, 94(3), 426-454.

[11] Carrington, W. J, Troske, K.R. (1998): "Segregation and the Black/White Wage gap", Journal of Labor Economics, vol. 16(2), pp. 231-260.

[12] Casella, A. and Hanaki, N. (2008): "Information channel in labor markets: On the resilence of referral hirings", Journal of Economic Behaviour and Organization, vol. 66 , pp. $492-513$. 
[13] Dustman, Ch., Glitz, A.,Vogel, Th. (2010): "Employment, Wages and the Economic Cycle. Difference between Immigrants and Natives", European Economic Review, vol. 54(1), pp. 1-17.

[14] Dustman, Ch., Glitz, A., Sch“onberg, U. (2011): " Referrals-based job search networks", mimeo .

[15] Farré, L., González, L., Ortega, F. (2011): "Immigration, Family Responsability and the labor Supply of Skilled native women", B.E. Journal Economic Analysis and Policy (contributions), vol.11(1), pp. 1-46.

[16] García Pérez, J. (2008): "La muestra continua de vidas laborales: una guía de uso para el analísis de transiciones", Revista de Economía Aplicada, vol. XVI E(1), pp. 5-28.

[17] Giuliano, L., Levine, D. and Leonard, J. (2009): "Manager Race and the Race of New Hires", Journal of Labor Economics, vol. 27(4), pp. 589-631.

[18] Goel, D., Lang, K. (2009): "Social Ties and the Job Search of Recent Immigrants", NBER working paper n. 15186.

[19] K. Lang, J.Y.K. Lehmann (2010): "Racial discrimination in the Labor Market: Theory and Empirics", Journal of Economic Literature forthcoming.

[20] K. Lang, M. Manove (2003): "Wage Announcements with a Continuum of Workers Types", Annales d'Economie et Statistique, vol. 71-72, pp. 223-244.

[21] K.Lang, M. Manove, W. Dickens (2005): "Racial discrimination in Labor Markets with Posted Wage Offers", American Economic Review, vol. 95(4), pp.1327 -1340.

[22] López-Mayan, C. (2010): "Demand for Post-compulsory Education: The Choice Between Academic and Vocational Tracks", mimeo.

[23] Montgomery, J.D. (1991): "Social Network and labor-market outcomes: toward an economic analysis", American Economic Review, vol.81, pp. 1408-1418.

[24] Nicodemo, C, (2009): "Heterogeneity across Immigrants in the Spanish labor Market: Advantage and Disadvantage", mimeo 
[25] Oyer, P. and Schaefer, S. (2011): "Personnel Economics: Hiring and Incentives", in Card, D. and Ashenfelter, O. (Ed): "Handbook of Labor Economics", vol. 4B, pp. 1769-1823, Elsevier.

[26] Peri, G., Sparber, C., (2009): "Task Specialization, Immigration and Wages", in American Economic Review: Applied Economics, Vol. 1(3), pp. 135-169.

[27] Wooldridge, J. (2006):" Introductory Econometrics. A Modern Approach", 3rd edition, Thomson South-Western. 
Table 2: Descriptive statistics for natives and immigrants

\begin{tabular}{|c|c|c|c|c|}
\hline & \multicolumn{2}{|c|}{ Low Skill } & \multicolumn{2}{|c|}{ High Skill } \\
\hline & Natives & Immigrants & Natives & Immigrants \\
\hline Age & 36 & 36 & 39 & 40 \\
\hline Education & & & & \\
\hline Primary & 0.23 & 0.33 & 0.06 & 0.06 \\
\hline Secondary & 0.67 & 0.60 & 0.55 & 0.64 \\
\hline Tertiary & 0.10 & 0.07 & 0.39 & 0.30 \\
\hline Country of birth & & & & \\
\hline Spanish & 87.48 & & 93.03 & \\
\hline EU-15 & & 2.04 & & 2.93 \\
\hline Rest of EU & & 1.50 & & 0.55 \\
\hline Africa & & 2.27 & & 0.51 \\
\hline Asia & & 0.33 & & 0.23 \\
\hline South Amer. & & 6.21 & & 2.54 \\
\hline Others & & 0.17 & & 0.3 \\
\hline Size Firms & & & & \\
\hline$<10$ & 0.07 & 0.06 & 0.09 & 0.09 \\
\hline between 10 and 49 & 0.49 & 0.48 & 0.53 & 0.51 \\
\hline between 50 and 100 & 0.44 & 0.46 & 0.38 & 0.40 \\
\hline Sector & & & & \\
\hline Agriculture & 0.004 & 0.01 & 0.01 & 0.00 \\
\hline Industry & 0.14 & 0.11 & 0.12 & 0.09 \\
\hline Building & 0.11 & 0.18 & 0.14 & 0.09 \\
\hline Trade & 0.08 & 0.06 & 0.08 & 0.10 \\
\hline Hotels & 0.22 & 0.31 & 0.10 & 0.22 \\
\hline Transportation & 0.03 & 0.05 & 0.02 & 0.03 \\
\hline Finance & 0.14 & 0.14 & 0.15 & 0.15 \\
\hline Civil Ser. & 0.09 & 0.02 & 0.15 & 0.05 \\
\hline Education & 0.03 & 0.02 & 0.06 & 0.09 \\
\hline Health & 0.08 & 0.06 & 0.11 & 0.13 \\
\hline Others & 0.08 & 0.04 & 0.06 & 0.07 \\
\hline Obs & 145851 & 20895 & 23401 & 1754 \\
\hline
\end{tabular}


Table 3: Multinomial logit

\begin{tabular}{l|ccrr}
\hline & \multicolumn{4}{|c}{ Low-skill hiring by race } \\
& Native & Latin & EU15 & Rest of EU \\
\hline \hline Manager( ref. cat.: African) & & & & \\
Native & $0.009^{* * *}$ & -0.004 & -0.001 & -0.001 \\
EU15 & 0.0020 & 0.002 & 0.001 & 0.002 \\
& $0.009^{*}$ & 0.002 & $0.005^{* * *}$ & $-0.003^{* * *}$ \\
Rest of Europe & 0.005 & 0.002 & 0.002 & 0.001 \\
Latin & -0.0004 & -0.002 & $0.016^{* *}$ & $-0.006^{* * *}$ \\
& 0.0061 & 0.003 & 0.006 & 0.001 \\
Share imm. at firm level & $0.017^{* * *}$ & $-0.003^{* * *}$ & -0.001 & -0.001 \\
& 0.006 & 0.002 & 0.001 & 0.002 \\
\hline Obs. & $0.185^{* * *}$ & $0.081^{* * *}$ & $0.045^{* * *}$ & $0.069^{* * *}$ \\
R2 & 0.003 & 0.002 & 0.001 & 0.002 \\
\hline \hline
\end{tabular}

$10 \%$. We control for regions, years and industry dummies. Robust standard errors.

Table 4: Linear Probability model

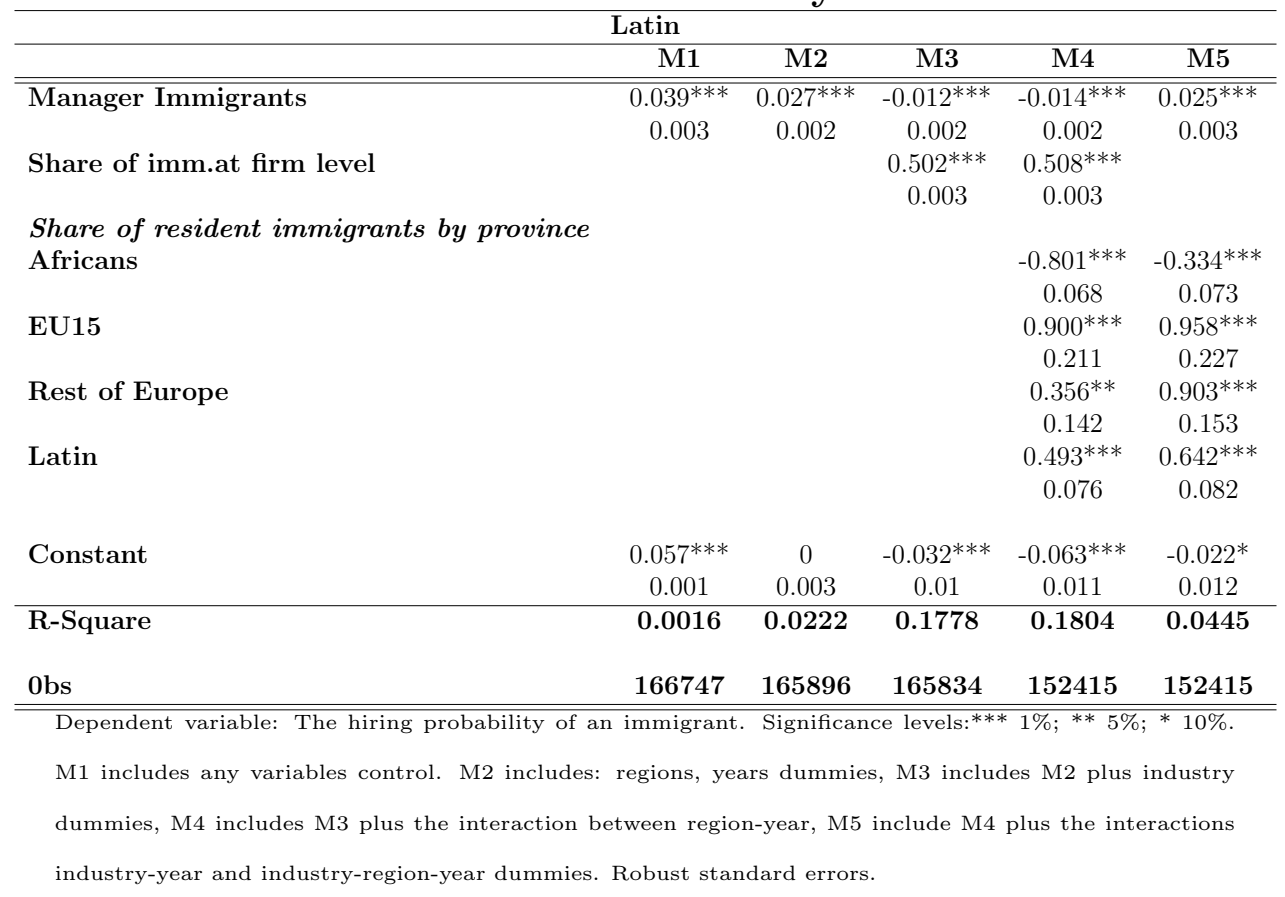


Table 5: Linear Probability model

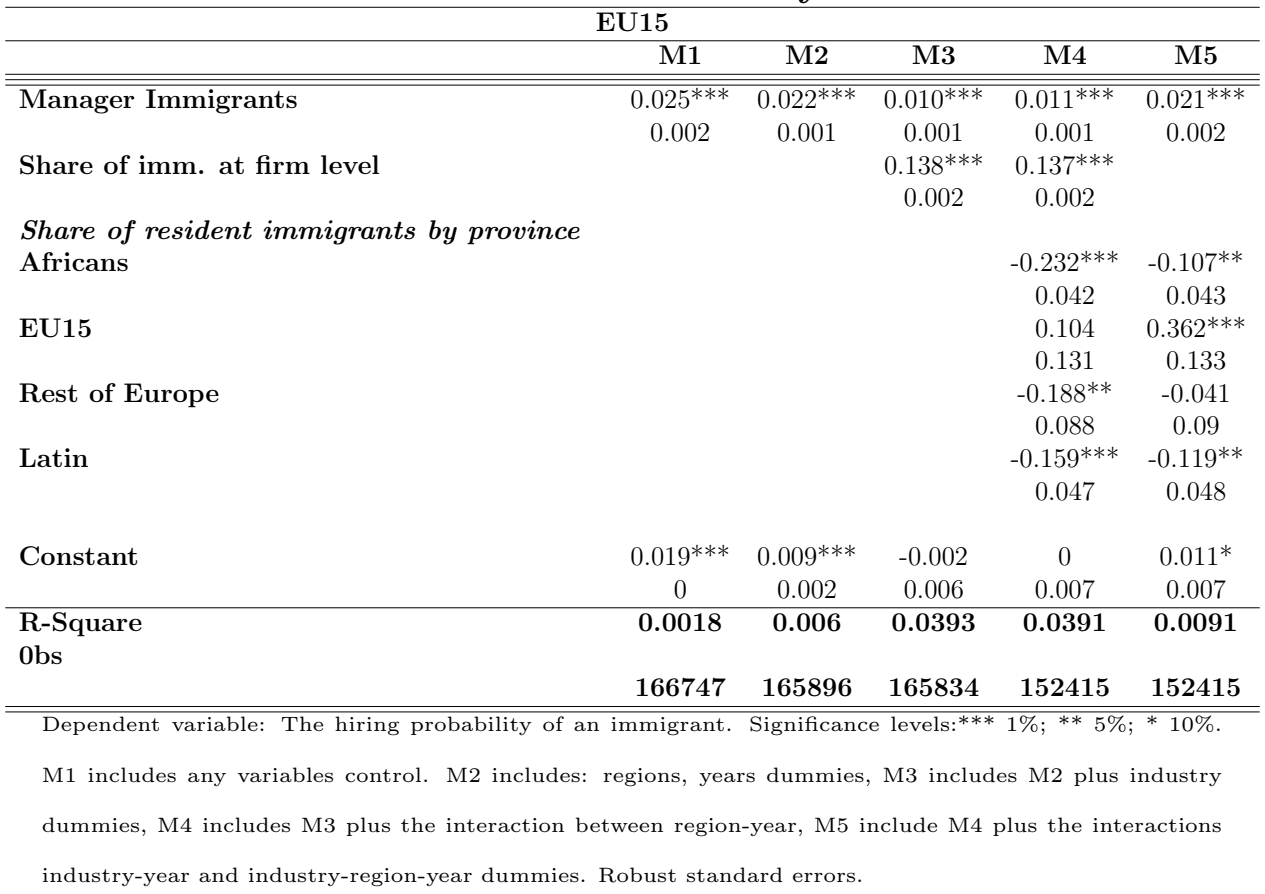

Table 6: Linear Probability model

\begin{tabular}{|c|c|c|c|c|c|}
\hline \multicolumn{6}{|c|}{ Rest of Europe } \\
\hline & M1 & M2 & M3 & M4 & M5 \\
\hline \multirow[t]{2}{*}{ Manager Immigrants } & $0.024^{* * *}$ & $0.022^{* * *}$ & $0.013^{* * *}$ & $0.014^{* * *}$ & $0.023^{* * *}$ \\
\hline & 0.002 & 0.001 & 0.001 & 0.001 & 0.001 \\
\hline \multirow[t]{2}{*}{ Share of imm. at firm level } & & & $0.121^{* * *}$ & $0.123^{* * *}$ & \\
\hline & & & 0.002 & 0.002 & \\
\hline \multicolumn{6}{|c|}{ Share of resident immigrants by province } \\
\hline \multirow[t]{2}{*}{ Africans } & & & & -0.061 & 0.052 \\
\hline & & & & 0.037 & 0.038 \\
\hline \multirow[t]{2}{*}{ EU15 } & & & & $-0.382^{* * *}$ & -0.15 \\
\hline & & & & 0.115 & 0.116 \\
\hline \multirow[t]{2}{*}{ Rest of Europe } & & & & $0.397 * * *$ & $0.529^{* * *}$ \\
\hline & & & & 0.077 & 0.079 \\
\hline \multirow[t]{2}{*}{ Latin } & & & & 0.065 & $0.101^{* *}$ \\
\hline & & & & 0.041 & 0.042 \\
\hline \multirow[t]{2}{*}{ Constant } & $0.013^{* * *}$ & -0.002 & $0.012^{* *}$ & $0.021 * * *$ & $0.031^{* * *}$ \\
\hline & 0.00 & 0.001 & 0.005 & 0.006 & 0.006 \\
\hline \multirow{2}{*}{$\begin{array}{l}\text { R-Square } \\
\text { 0bs }\end{array}$} & 0.0023 & 0.0106 & 0.0428 & 0.0437 & 0.0124 \\
\hline & 166747 & 165896 & 165834 & 152415 & 152415 \\
\hline
\end{tabular}

M1 includes any variables control. M2 includes: regions, years dummies, M3 includes M2 plus industry

dummies, M4 includes M3 plus the interaction between region-year, M5 include M4 plus the interactions

industry-year and industry-region-year dummies. Robust standard errors. 
Table 7: Linear Probability model

\begin{tabular}{|c|c|c|c|c|c|}
\hline \multicolumn{6}{|c|}{ Africans } \\
\hline & M1 & M2 & M3 & M4 & M5 \\
\hline \multirow[t]{2}{*}{ Manager Immigrants } & $0.009^{* * *}$ & $0.008^{* * *}$ & $-0.009^{* * *}$ & $-0.010^{* * *}$ & $0.007^{* * *}$ \\
\hline & 0.002 & 0.002 & 0.001 & 0.002 & 0.002 \\
\hline \multirow[t]{2}{*}{ Share of imm. at firm level } & & & $0.217^{* * *}$ & $0.216^{* * *}$ & \\
\hline & & & 0.002 & 0.002 & \\
\hline \multicolumn{6}{|c|}{ Share of resident immigrants by province } \\
\hline \multirow[t]{2}{*}{ Africans } & & & & $0.907^{* * *}$ & $0.906^{* * *}$ \\
\hline & & & & 0.044 & 0.045 \\
\hline \multirow[t]{2}{*}{ EU15 } & & & & $-0.291^{* *}$ & 0.117 \\
\hline & & & & 0.136 & 0.14 \\
\hline \multirow[t]{2}{*}{ Rest of Europe } & & & & $-0.607^{* * *}$ & $-0.375^{* * *}$ \\
\hline & & & & 0.092 & 0.095 \\
\hline \multirow[t]{2}{*}{ Latin } & & & & 0.003 & 0.066 \\
\hline & & & & 0.049 & 0.051 \\
\hline \multirow[t]{2}{*}{ Constant } & $0.021^{* * *}$ & $0.011^{* * *}$ & -0.008 & -0.009 & 0.009 \\
\hline & 0.001 & 0.002 & 0.006 & 0.007 & 0.007 \\
\hline \multirow{2}{*}{$\begin{array}{l}\text { R-Square } \\
\text { Obs }\end{array}$} & 0.0002 & 0.0079 & 0.0837 & 0.090 & 0.0242 \\
\hline & 166747 & 165896 & 165834 & 152415 & 152415 \\
\hline
\end{tabular}

Dependent variable: The hiring probability of an immigrant. Significance levels:*** $1 \%$; ${ }^{* *} 5 \%$; ${ }^{*} 10 \%$.

M1 includes any variables control. M2 includes: regions, years dummies, M3 includes M2 plus industry dummies, M4 includes M3 plus the interaction between region-year, M5 include M4 plus the interactions industry-year and industry-region-year dummies. Robust standard errors.

Table 8: Robustness check

\begin{tabular}{|c|c|c|c|c|}
\hline \multicolumn{5}{|c|}{ Latin } \\
\hline & M1 & M2 & M3 & M4 \\
\hline & \multicolumn{2}{|c|}{ Establishment Fixed Effects } & \multicolumn{2}{|c|}{ Firm Fixed Effects } \\
\hline \multirow[t]{2}{*}{ Manager Immigrant } & $0.010^{*}$ & $0.011^{*}$ & 0,007 & 0,003 \\
\hline & 0,005 & 0,005 & 0,005 & 0,005 \\
\hline \multirow[t]{2}{*}{ Share of imm. in the firm } & & $0.486^{* * *}$ & & $0.602^{* * *}$ \\
\hline & & 0,156 & & 0,011 \\
\hline \multicolumn{5}{|c|}{ Share of resident immigrants by province } \\
\hline \multirow[t]{2}{*}{ African } & $-0.686^{* * *}$ & $-0.686^{* * *}$ & $-0.171^{*}$ & $-0.532^{* * *}$ \\
\hline & 0,169 & 0,169 & 0,097 & 0,096 \\
\hline \multirow[t]{2}{*}{ EU15 } & $0.975^{* * *}$ & $0.987^{* * *}$ & $0.914^{* * *}$ & $0.907^{* * *}$ \\
\hline & 0,329 & 0,329 & 0,302 & 0,299 \\
\hline \multirow[t]{2}{*}{ Rest of Europe } & $0.997^{* * *}$ & $0.991^{* * *}$ & $0.926^{* * *}$ & $0.609 * * *$ \\
\hline & 0,222 & 0,222 & 0,202 & 0,2 \\
\hline \multirow[t]{2}{*}{ Latin } & $0.808^{* * *}$ & $0.805^{* * *}$ & $0.901^{* * *}$ & $0.817^{* * *}$ \\
\hline & 0,107 & 0,107 & 0,1 & 0,099 \\
\hline \multirow[t]{2}{*}{ Constant } & 0,416 & 0,295 & 0,023 & $-0.072^{*}$ \\
\hline & 2,891 & 2,892 & 0,039 & 0,039 \\
\hline Obs & 152415 & 152415 & 152415 & 152415 \\
\hline Sigmau & 0,220 & 0,181 & 0,176 & 0,142 \\
\hline Sigmae & 0,217 & 0,217 & 0,220 & 0,217 \\
\hline Rho & 0,507 & 0,409 & 0,390 & 0,299 \\
\hline
\end{tabular}

Included controls: regions, years and industry dummies. We also include these interaction terms: regionyear, industry-year, region-industry-year dummies. Robust standard errors. 
Table 9: Robustness check

\begin{tabular}{|c|c|c|c|c|}
\hline \multicolumn{5}{|c|}{ EU15 } \\
\hline & M1 & M2 & M3 & M4 \\
\hline & \multicolumn{2}{|c|}{ Establishment Fixed Effects } & \multicolumn{2}{|c|}{ Firm Fixed Effects } \\
\hline Manager Immigrant & $0.005^{*}$ & $0.006^{*}$ & $0.005^{*}$ & 0.004 \\
\hline & 0.003 & 0.003 & 0.003 & 0.003 \\
\hline \multirow[t]{2}{*}{ Share of imm. in the firm } & & $0.229^{* *}$ & & $0.104^{* * *}$ \\
\hline & & 0.093 & & 0.006 \\
\hline Share of resident immigrants by province & & & & 0.006 \\
\hline \multirow[t]{2}{*}{ African } & 0.035 & 0.034 & 0.036 & -0.027 \\
\hline & 0.102 & 0.102 & 0.058 & 0.058 \\
\hline \multirow[t]{2}{*}{ EU15 } & 0.146 & 0.152 & 0.119 & 0.083 \\
\hline & 0.198 & 0.198 & 0.18 & 0.18 \\
\hline \multirow[t]{2}{*}{ Rest of Europe } & $-0.250^{*}$ & $-0.253^{*}$ & 0.014 & -0.04 \\
\hline & 0.133 & 0.133 & 0.121 & 0.121 \\
\hline \multirow[t]{2}{*}{ Latin } & 0.024 & 0.023 & $-0.152^{* *}$ & $-0.167^{* * *}$ \\
\hline & 0.064 & 0.064 & 0.06 & 0.06 \\
\hline \multirow[t]{2}{*}{ Constant } & 2.573 & 2.516 & 0.028 & 0.012 \\
\hline & 1.735 & 1.735 & 0.023 & 0.023 \\
\hline Obs & 152415 & 152415 & 152415 & 152415 \\
\hline Sigmau & 0.227 & 0.222 & 0.111 & 0.103 \\
\hline Sigmae & 0.130 & 0.130 & 0.131 & 0.131 \\
\hline Rho & 0.752 & 0.744 & 0.416 & 0.384 \\
\hline
\end{tabular}

Included controls: regions, years and industry dummies. We also include these interaction terms: region-

year, industry-year, region-industry-year dummies. Robust standard errors.

Table 10: Robustness check

\begin{tabular}{|c|c|c|c|c|}
\hline \multicolumn{5}{|c|}{ Rest of Europe } \\
\hline & M1 & M2 & M3 & M4 \\
\hline & \multicolumn{2}{|c|}{ Establishment Fixed Effects } & \multicolumn{2}{|c|}{ Firm Fixed Effects } \\
\hline \multirow[t]{2}{*}{ Manager Immigrant } & 0.000 & 0.000 & -0.002 & -0.002 \\
\hline & 0.003 & 0.003 & 0.002 & 0.002 \\
\hline \multirow[t]{2}{*}{ Share of imm. in the firm } & & -0.064 & & $0.051^{* * *}$ \\
\hline & & 0.082 & & 0.006 \\
\hline \multicolumn{5}{|c|}{ Share of resident immigrants by province } \\
\hline \multirow[t]{2}{*}{ African } & 0.03 & 0.03 & -0.016 & -0.047 \\
\hline & 0.089 & 0.089 & 0.051 & 0.051 \\
\hline \multirow[t]{2}{*}{ EU15 } & -0.073 & -0.075 & -0.193 & -0.211 \\
\hline & 0.173 & 0.173 & 0.157 & 0.157 \\
\hline \multirow[t]{2}{*}{ Rest of Europe } & $0.314^{* * *}$ & $0.315^{* * *}$ & $0.380^{* * *}$ & $0.353^{* * *}$ \\
\hline & 0.117 & 0.117 & 0.105 & 0.105 \\
\hline \multirow[t]{2}{*}{ Latin } & $-0.096^{*}$ & $-0.096^{*}$ & -0.028 & -0.035 \\
\hline & 0.056 & 0.056 & 0.052 & 0.052 \\
\hline \multirow[t]{2}{*}{ Constant } & $11.549^{* * *}$ & $11.565^{* * *}$ & -0.006 & -0.014 \\
\hline & 1.522 & 1.522 & 0.02 & 0.021 \\
\hline Obs & 152415 & 152415 & 152415 & 152415 \\
\hline Sigmau & 0.886 & 0.887 & 0.104 & 0.100 \\
\hline Sigmae & 0.114 & 0.114 & 0.114 & 0.114 \\
\hline Rho & 0.984 & 0.984 & 0.452 & 0.432 \\
\hline
\end{tabular}

Included controls: regions, years and industry dummies. We also include these interaction terms: region-

year, industry-year, region-industry-year dummies. Robust standard errors. 
Table 11: Robustness check

\begin{tabular}{|c|c|c|c|c|}
\hline \multicolumn{5}{|c|}{ Africans } \\
\hline & M1 & M2 & M3 & M4 \\
\hline & \multicolumn{2}{|c|}{ Establishment Fixed Effects } & \multicolumn{2}{|c|}{ Firm Fixed Effects } \\
\hline \multirow[t]{2}{*}{ Manager Immigrant } & -0.0010 & -0.0010 & 0.0000 & -0.0010 \\
\hline & 0.003 & 0.003 & 0.003 & 0.003 \\
\hline \multirow[t]{2}{*}{ Share of imm. in the firm } & & $0.214^{* *}$ & & $0.178^{* * *}$ \\
\hline & & 0.094 & & 0.006 \\
\hline \multicolumn{5}{|c|}{ Share of resident immigrants by province } \\
\hline \multirow[t]{2}{*}{ African } & $0.714^{* * *}$ & $0.713^{* * *}$ & $0.791^{* * *}$ & $0.683^{* * *}$ \\
\hline & 0.102 & 0.102 & 0.058 & 0.058 \\
\hline \multirow[t]{2}{*}{ EU15 } & 0.307 & 0.312 & 0.028 & -0.033 \\
\hline & 0.198 & 0.198 & 0.181 & 0.181 \\
\hline \multirow[t]{2}{*}{ Rest of Europe } & -0.039 & -0.042 & -0.023 & -0.117 \\
\hline & 0.134 & 0.134 & 0.121 & 0.121 \\
\hline \multirow[t]{2}{*}{ Latin } & $0.113^{*}$ & $0.112^{*}$ & $0.151^{* *}$ & $0.126^{* *}$ \\
\hline & 0.065 & 0.065 & 0.06 & 0.06 \\
\hline \multirow[t]{2}{*}{ Constant } & $3.452^{* *}$ & $3.399^{*}$ & 0.002 & -0.026 \\
\hline & 1.741 & 1.741 & 0.024 & 0.024 \\
\hline Obs & 152415 & 152415 & 152415 & 152415 \\
\hline Sigmau & 0.316 & 0.309 & 0.111 & 0.103 \\
\hline Sigmae & 0.131 & 0.131 & 0.132 & 0.131 \\
\hline Rho & 0.854 & 0.848 & 0.416 & 0.379 \\
\hline
\end{tabular}

Included controls: regions, years and industry dummies. We also include these interaction terms: region-

year, industry-year, region-industry-year dummies. Robust standard errors. 